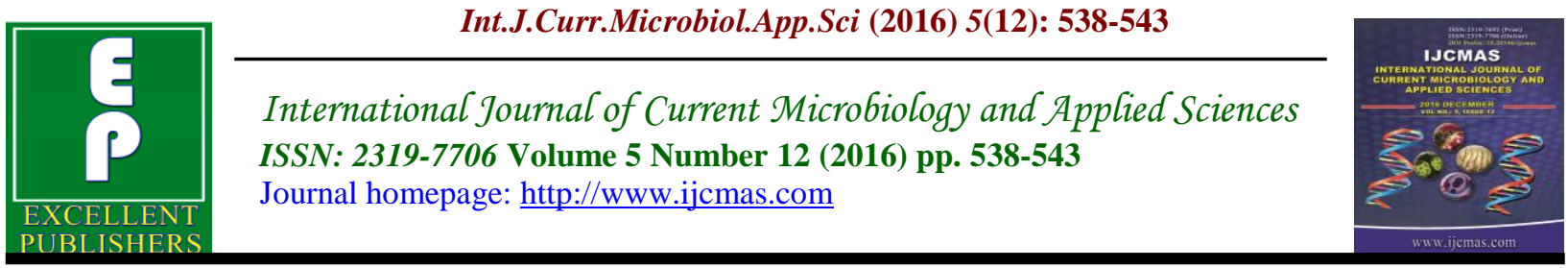

Original Research Article

http://dx.doi.org/10.20546/ijcmas.2016.512.059

\title{
Progressive Decline in Pulmonary Functions in Adolescents with Chronic Hepatitis C Infection
}

\author{
S.M. Hassan ${ }^{1}$, Heba Mohammed El Ashry ${ }^{2}$ and S. Abd-Elsalam ${ }^{2}$ \\ ${ }^{1}$ Pediatric Department, Faculty of Medicine, Tanta University, Egypt \\ ${ }^{2}$ Tropical Medicine Department, Faculty of Medicine, Tanta University, Egypt \\ *Corresponding author
}

Keywords

Chronic

Hepatitis B and C,

FEV1,

FVC,

Pulmonary functions.

Article Info

Accepted:

18 November 2016

Available Online:

10 December 2016

\section{A B S T R A C T}

Chronic hepatitis $\mathrm{C}$ infection is considered now a multi-system disease, affecting nearly all body system. Hepatic affection of such viruses are widely evaluated while extra-hepatic manifestations (including lungs)still need more studies, especially in children and adolescents . To evaluate if chronic HCV (CHCV) infection without treatment is associated with progressive deterioration of pulmonary functions. Fifty adolescent patients with CHCV infection (12-18 years) and 50 control health subjects included in the study, with full hepatic evaluation beside pulmonary function tests (PFTs) at the start of the study. PFTs were repeated in patient group after 6 and 12 months and evaluated in comparison to start results and to control group. There was a gradual deterioration of PFT in adolescent patients with CHCV infection reached a significant levels(FEV1 $89 \pm$ $1.3, \mathrm{FVC} 88 \pm 0.8, \quad \mathrm{FEV} 1 / \mathrm{FVC} 91 \pm 1.1$ ) when compared to healthy control group(FEV1 $96 \pm 1.9, \mathrm{FVC} 95 \pm 1.2$, FEV1/FVC $97 \pm 1.1$ ) with $\mathrm{P}$ value $(0.02,0.03,0.01)$ respectively. Progressive decline in pulmonary functions is observed in adolescents with chronic $\mathrm{HCV}$ infection, but more researches are needed to further explore such deteriorations.

\section{Introduction}

Hepatitis $\mathrm{C}$ virus (HCV) is a worldwide major health problem, affecting nearly 200 million people, and considered to be one of the leading top ten lethal infectious agents (Elwan et al., 2016). Infection by either of them can occur, but also co infection is widely recorded because of similar modes of transfer (e.g. blood products transfusion, sexual routes, drug abuse, needle injury).Co infection causes more health hazards than single infection. Liver injuries caused by such viruses are well known and widely evaluated in researches, while extra hepatic manifestations are still evolving, including skin, kidneys, CNS, blood, cardiovascular system, endocrine, oncologic., etc. (Zignego, 1999; 2008). Pulmonary manifestations of hepatitis $\mathrm{C}$ viruses (HCV) are recently attack the attention of researchers, especially in adults with chronic HCV infection after treatment (Ueda et al., 1992), with controversy results. Most of the studies record decline in pulmonary functions in adults with chronic HCV due to different mechanisms, either direct effect (induction 
of interstitial fibrosis activation of asthma (Yamaguchi et al., 1997), COPD (Silva et al., 2010), or indirect effects (through induction of cryoglobulinemia (Ferri et al., 2004), and side effects of therapy (Zignego, 2007).

Despite the rapid increase in number of patients with HCV worldwide, the pulmonary complications of such infections not widely investigated and explained in adults, most of reports are casa-study, and up to our knowledge, no previous research evaluate the pulmonary complications in children and adolescents chronically infected with HCV.

The aim of this study was to evaluate pulmonary functions (FEV1.FVC. FEV/ $\mathrm{FVC}$ ) in adolescents with chronic $\mathrm{HCV}$ infection.

\section{Subjects and Methods}

\section{Subjects}

This prospective randomized control study included 50 adolescent patients (aged 12-18 ys) with chronic hepatitis-C virus ( $\mathrm{CHCV}$ ) infection and 50 healthy subjects of matched age and sex as a control group. All subjects attended OPD clinics for hepatology and gastroenterology, Tanta University, Egypt; during the period from September 2014 till September 2015.

All subjects should be: non-smokers, with no chronic lung diseases (eg. asthma, COPD), have normal liver function tests at the begging of the study, normal liver ultrasound, and normal liver fibroscan (for CHCV patients only). Hepatitis patient group not received treatment for $\mathrm{CHCV}$ and had negative HBsAg and negative anti-HBc, with positive hepatitis $\mathrm{C}$ antibody (anti$\mathrm{HBc}$ ) test.
All patients were diagnosed as $\mathrm{HCV}$ for at least one year before start of the study.

In CHCV group, study began with 50patients, but only 34 patients completed the study ( 9 patients started treatment during the study period, 7 patients missed).

Written consent had been taken from all patients (or their care-givers) and underwent ethical committee

\section{Methods}

All patients and control group subjected to

1-Full history taking

2-Complete medical examination

3-Liver function tests

4-Hepatitis B surface antigen ( $\mathrm{HBsAg}$ ) and Hepatitis B core antibodies (antiHBc)

5-Hepatitis $\mathrm{C}$ antibody (anti-HCV)

5-Abdominal ultrasonography

6-Liver fibroscan for hepatitis group only

7-Pulmonary function tests (PFTs) by Spirometry, FEV1.FVC, and FEV1/FVC: done for all subjects at the begging of the study, then done only for patient group after 6 and 12 months. PFTs measured at the morning 9 AM-11 AM, the best of 3 reading was recorded and compared to the best predictive value depending on age $(\mathrm{kg})$, height $(\mathrm{cm})$ and sex.

Data of all subjects were collected, analyzed according to STATA version 11.

\section{Results and Discussion}

Data of CHCV patients who completed the study (34) and control group (50) collected in tables (1-6)

Fifty adolescent patients with chronic hepatitis $\mathrm{C}$ infection met the inclusion criteria at the start of the study, only 34 complete the study according to such 
criteria, 50 healthy subjects of nonsignificant difference regarding demographic data (age, sex, height, BMI, waist: hip ratio) (Table 1) evaluated as control group.

At the start of the study, PFTs in patient group were lower (FEV1 $94 \% \pm 2.1, \mathrm{FVC}$ $95 \% \pm 0.9$, FEV1/FVC $97 \pm 0.8$ ) but nonsignificant, when compared to control group (FEV1 $96 \% \pm 1.9$, FVC $95 \% \pm 1.2$, FEV1/FVC $97 \pm 1.1$ ) with $\mathrm{P}$ value 0.86 , $0.77,1.05$ respectively (Table 2 ).

After 6 months from start of the study, PFTs in patient group were slightly lower (FEV1 $93 \% \pm 1.7$, FVC $95 \% \pm 1.4$, FEV1/FVC 95 \pm 1.0 ) but non-significant, when compared to control group (FEV1 $94 \% \pm 2.1, \mathrm{FVC} 95$ $\% \pm 0.9, \mathrm{FEV} 1 / \mathrm{FVC} 97 \pm 0.8)$ with $\mathrm{P}$ value $0.89,0.87,1.1$ respectively(Table 3 ).

After 12 months from start of the study, more deteriorations in PFTs in patient group (FEV1 $89 \% \pm 1.3$, FVC $88 \% \pm 0.8$, FEV1/FVC $91 \pm 1.1$ ) but non-significant, when compared to their PFTs recorded 6 months earlier (FEV1 $93 \% \pm 1.7$, FVC $95 \%$ $\pm 1.4, \mathrm{FEV} 1 / \mathrm{FVC} 95 \pm 1.0$ ) with $\mathrm{P}$ value $0.06,0.07,0.1$ respectively (Table 4 ), and still not significantly lower when compared to their PFTs recorded at the start of the study, 12 months earlier, with $P$ value $0.08,0.07,0.0 .8$ respectively (Table 5 ).

Of interest, PFTs recorded in adolescent patients at the end of our study (after 12 months) became significantly lower (FEV1 $89 \% \pm 1.3$, FVC $88 \% \pm 0.8$, FEV1/FVC 91 \pm 1.1) when compared to control group(FEV1 $96 \% \pm 1.9$, FVC $95 \% \pm 1.2$, FEV1/FVC $97 \pm 1.1$ )with $P$ value $0.02,0.03$, 0.01 respectively (Table.6) Hepatitis $C$ virus infection is a worldwide health problem. Due to lack of effective vaccine (up till now), beside wide scale of methods of transmission, the disease affects more and more victims of all ages. Although the liver is the main target of the $\mathrm{HCV}$, chronic $\mathrm{HCV}$ infection is considered a multisystem disease, affecting nearly all body organs, contributing to wide range of presentations and complications. Association between $\mathrm{CHCV}$ infection with pulmonary functions and diseases not sufficiently evaluated, especially in children and adolescents. The present study aimed at evaluating the progress changes in pulmonary functions in adolescents with chronic $\mathrm{HCV}$ infection not received interferon or ribavirin.

In adults with $\mathrm{CHCV}$ infection, limited studies evaluated such infection and chest, with controversy results. While Kanazawa et al., reported a greater decline in FEV1 in COPD adult patients who had $\mathrm{HCV}$ infection in a small prospective cohort study, however, nearly half of the patients received interferon therapy which affect perse lung functions, making a confounding effect on the result. On the other hand, Tueber et al., (2002) studied 178 noncirrhotic patients with chronic viral hepatitis and found no significant impairment of FEV1 and FVC.

Minakata et al., (2010), in a large study in Japan found no significant association between both diseases, while Silva et al., (2010) recorded a higher prevalence of COPD in HCV-positive individuals compared to negative ones. Up to our knowledge, this is the first study evaluated pulmonary functions in adolescent patients with $\mathrm{CHCV}$.

In our single-center prospective pilot study, we selected adolescent patients with CHCV infection who not received interferon or ribavirin to concisely evaluate the effect of viral infection on pulmonary functions (FEV1, FVC, FEV1/FVC). 
Table.1 Demographic data of studied groups at the start of the study

\begin{tabular}{|l|l|l|l|}
\hline & Patient $(\mathrm{n}=34)$ & Control $(\mathrm{n}=50)$ & P value \\
\hline Age $($ years) Mean $( \pm$ SD) & $15.4 \quad 2.1$ & $15.2 \quad 2,6$ & 1.3 \\
\hline Sex $($ M:F) & $18: 16$ & $26: 24$ & 0.9 \\
\hline Heigh(cm) Mean $( \pm$ SD) & $155.7(9.77)$ & $157.5(9.6)$ & 1.2 \\
\hline BMI Mean( \pm SD) & $26.89(4,97)$ & $26.44(6.05)$ & 2 \\
\hline Waist:hipratio;Mean $( \pm$ SD) & $0.93(0.006)$ & $0.91(0.09)$ & 1.7 \\
\hline
\end{tabular}

$\mathrm{P}$ significant if $<0.05$

No significant difference between patients and control group regarding demographic data at the start of the study.

Table.2 Pulmonary functions in studied groups at the start of the study

\begin{tabular}{|l|l|l|l|}
\hline & Patient $(\mathrm{n}=34)$ & Control $(\mathrm{n}=50)$ & $\mathrm{P}$ value \\
\hline FEV1(\%):Mean( \pm SD) & $94(2.1)$ & $96(1.9)$ & 0.86 \\
\hline FVC(\%):Mean( \pm SD) & $95(0.9)$ & $95(1.2)$ & 0.77 \\
\hline FEV1/FVC: & $97(0.8)$ & $97(1.1)$ & 1.05 \\
Mean( \pm SD) & & & \\
\hline
\end{tabular}

$\mathrm{P}$ significant if $<0.05 \mathrm{FEV} 1$ forced expiratory volume in 1 secondFVC forced vital capacity No significant difference between patients and control group regarding pulmonary functions at the start of the study.

Table.3 Pulmonary functions in patient group after 6 months from the start of the study

\begin{tabular}{|l|l|l|l|}
\hline & Patient $(\mathrm{n}=34)$ at start & $\begin{array}{l}\text { Patient }(\mathrm{n}=34) \text { after 6 } \\
\text { months }\end{array}$ & P value \\
\hline FEV1(\%):Mean( \pm SD) & $94(2.1)$ & $93(1.7)$ & 0.89 \\
\hline FVC $(\%):$ Mean( \pm SD) & $95(0.9)$ & $93(1.4)$ & 0.87 \\
\hline $\begin{array}{l}\text { FEV1/FVC: } \\
\text { Mean }( \pm \text { SD })\end{array}$ & $97(0.8)$ & $95(1.0)$ & 1.1 \\
\hline
\end{tabular}

$\mathrm{P}$ significant if $<0.05 \mathrm{FEV} 1$ forced expiratory volume in 1 secondFVC forced vital capacity No significant difference regarding pulmonary functions at the start of the study compared to after 6 months from start in patient group.

Table.4 Pulmonary functions in patient group after 6 months and 12 months from the start of the study

\begin{tabular}{|c|c|c|c|}
\hline & $\begin{array}{l}\text { Patient }(n=34) \text { after } 6 \\
\text { months }\end{array}$ & $\begin{array}{l}\text { Patient }(n=34) \text { after } 12 \\
\text { months }\end{array}$ & $P$ value \\
\hline FEV1(\%):Mean $( \pm$ SD) & $93(1.7)$ & $89(1.3)$ & 0.09 \\
\hline FVC(\%):Mean $( \pm$ SD) & $93(1.4)$ & $88(0.8)$ & 0.07 \\
\hline $\begin{array}{l}\text { FEV1/FVC: } \\
\text { Mean }( \pm \text { SD })\end{array}$ & $95(1.0)$ & $91(1.1)$ & 0.1 \\
\hline
\end{tabular}

P significant if $<0.05 \mathrm{FEV} 1$ forced expiratory volume in 1 secondFVC forced vital capacity No significant difference regarding pulmonary functions in patient group after 6 months when compared to pulmonary functions after 12 months from the start of the study 
Table.5 Pulmonary functions in patient group at the end of the study compared to pulmonary functions at the begging of the study

\begin{tabular}{|l|l|l|l|}
\hline & Patient $(\mathrm{n}=34)$ & patient $(\mathrm{n}=34)$ & P value \\
\hline FEV1(\%):Mean( \pm SD) & $89(1.3)$ & $94(2.1)$ & 0.08 \\
\hline FVC(\%):Mean( \pm SD) & $88(0.8)$ & $95(0.9)$ & 0.07 \\
\hline $\begin{array}{l}\text { FEV1/FVC: } \\
\text { Mean( }( \pm \text { SD) }\end{array}$ & $91(1.1)$ & $97(0.8)$ & 0.08 \\
\hline
\end{tabular}

P significant if $<0.05 \mathrm{FEV} 1$ forced expiratory volume in 1 secondFVC forced vital capacity

No significant difference regarding pulmonary functions in patient group after 12 months when compared to pulmonary functions at the start of the study

Table.6 Pulmonary functions in studied groups at the end (after 12 months) of the study

\begin{tabular}{|l|l|l|l|}
\hline & Patient $(\mathrm{n}=34 \mathrm{we})$ & Control(n=50) & P value \\
\hline FEV1(\%):Mean( \pm SD) & $89(1.3)$ & $96(1.9)$ & $0.02^{*}$ \\
\hline FVC(\%):Mean( \pm SD) & $88(0.8)$ & $95(1.2)$ & $0.03^{*}$ \\
\hline $\begin{array}{l}\text { FEV1/FVC: Mean } \pm \\
\text { (SD) }\end{array}$ & $91(1.1)$ & $97(1.1)$ & $0.01^{*}$ \\
\hline
\end{tabular}

P significant if $<0.05 \mathrm{FEV} 1$ forced expiratory volume in 1 secondFVC forced vital capacity

There were significant difference regarding pulmonary functions in patient group after 12 months when compared to pulmonary functions of control group.

At the beginning of our study, our patients showed lower but non-significant PFT when compared to control group, although there were no history or clinical picture of any disease can affect PFT in such patients, except $\mathrm{CHCV}$ infection. With serial follow up of PFT, gradual deterioration recorded, and after 12 months of follow up,PFT decrease to a significant levels compared to control group, and still lower (not significant) when compared to patients at the start of our study. Explanation of such deterioration not found in the literature, especially most recorded studies done in adults and as a case-record .Biological mechanisms can be used for explanation, as viral hepatitis infection associated with increase in cryologlobulines, which in turn can lead to development of pulmonary sarcoidosis an interstitial lung disease (2861).

A larger study with longer period follow up are needed to evaluate the long term effects of hepatitis virus infection on lungs of both children and adults.

\section{Competing interest}

All authors declare they have no competing interest

\section{Abbreviations}

HBV: hepatitis B virus

$\mathrm{HCV}$ : hepatitis $\mathrm{C}$ virus

PFT: pulmonary function test

FEV1: forced expiratory volume in 1 second

FVC: forced vital capacity

COPD: chronic obstructive pulmonary disease

Anti-HBc: hepatitis B core antibody

HBsAg: hepatitis B surface antigen

Anti-HCV: hepatitis $\mathrm{C}$ antibody

$\mathrm{CHCV}$ : chronic hepatitis $\mathrm{C}$ virus 


\section{References}

Elwan, N., Elfert, A., Abd-Elsalam, S. 2016. Study of Hepatic Steatosis Index in Patients with Chronic HCV Infection. Int. J. Curr. Microbiol. App. Sci., 5(5): 266-274.

Ferri, C., Sebastiani, M., Giuggioli, D., et al. 2004. Mixed cryoglobulinemia: demographic, clinical and serologic features and survival in 231 patients. Semin Arthritis Rheum., 33(6): 355-74.

Kanazawa, H., Yoshikawa. 2004. Accelerated decline in lung function and impaired reversibility with salbutamol in asthmatic patients with chronic hepatitis $\mathrm{C}$ virus infection: a 6-years follow-up study. Am. J. Med., 116(11): 749-52.

Minakata, Y., Ueda, H., Akamatsu, K., et al. 2010. High COPD prevalence in patients with liver disease. Intern. Med., 49(24): 2687-91.

Silva, D.R., Stifft, J., Cheinquer, H., et al. 2010. Prevalence of hepatitis $C$ virus infection in patients with COPD. Epidemiol. Infect., 138(2): 167-73.

Teuber, G., Teupe, C., Dietrich, C.F., et al. 2002. Pulmonary dysfunction in non- cirrhotic patients with chronic viral hepatitis. Eur. J. Intern. Med., 13(5): 311-8.

Ueda, T., Ohta, K., Suzuki, N., et al. 1992. Idiopathic pulmonary fibrosis and high prevalence of serum antibodies to hepatitis C virus. Am. Rev. Respir. Dis., 146(1): 266-8.

Yamaguchi, S., Kubo, K., Fujimoto, K., et al. 1997. Analysis of bronchoalveolar lavage fluid in patients with chronic hepatitis $\mathrm{C}$ before and after treatment with interferon alpha. Thorax, 52(1): 33-7.

Zignego, A.L., Brechot, C. 1999. Extrahepatic manifestations of $\mathrm{HCV}$ infection: facts and controversies. Hepatol., 31(2): 369-76.

Zignego, A.L., Giannini, C., Ferri, C. 2007. hepatitis $\mathrm{C}$ virus-related lymphoproliferative disorders: an overview. World J. Gastroenterol., 13(17): 2467-78

Zignego, A.L., Piluso, A., Giannini, C. 2008. HBV and HCV chronic infection: autoimmune manifestations and lymphoproliferation. Autoimmune Rev., 8(2): 107-11.

\section{How to cite this article:}

Hassan, S.M., Heba Mohammed El Ashry and S. Abd-Elsalam. 2016. Progressive Decline in Pulmonary Functions in Adolescents with Chronic Hepatitis C Infection. Int.J.Curr.Microbiol.App.Sci. 5(12): 538-543. doi: http://dx.doi.org/10.20546/ijcmas.2016.512.059 